by Ian Lambert ${ }^{1}$, Ray Durrheim, Marcio Godoy, Mxolisi Kota, Pat Leahy, John Ludden, Edmund Nickless, Roland Oberhaensli, Wang Anjian, Neil Williams

\title{
Resourcing Future Generations: A proposed new IUGS initiative
}

\author{
${ }^{1}$ Secretary General, International Union of Geological Sciences. E-mail: ian.lambert7@gmail.com
}

\section{Introduction}

The International Union of Geological Sciences (IUGS) was formed in 1961 as the umbrella organisation to represent the geosciences globally. It is a non-political, non-governmental and notfor-profit organization with 120 member countries, which:

1. Promotes development of the geosciences through the support of international, broad-based, and interdisciplinary scientific studies relevant to the entire System Earth;

2. Applies the results of these and other studies to preserving Earth's natural environment, using all natural resources wisely and improving the prosperity of nations and the quality of human life;

3. Strengthens public awareness of geology and advances geological education in the widest sense;

4. Develops and promulgates geoscience standards, including for information management and chronostratigraphy; and

5. Through its membership of the International Council for Science (ICSU), has good links to a wide range of scientific and technical expertise.

The Executive Committee has decided to provide an additional focus for IUGS through an international initiative aimed at meeting the needs for natural resources in the long term. This reflects recommendations of the IUGS strategic plan (http://iugs.org/ index.php?page $=$ documents) and the final report of the Global Geoscience Initiative (GGI) http://www.agiweb.org/members/ggi/ GGIFinalReport.pdf) - both of which recognize that population growth and the aspirations of developing nations mean it is a priority to secure new mineral, energy and water resources ${ }^{1}$ for the future, while meeting the environmental and social imperatives for sustainable development:

- Even with maximum achievable levels of efficiencies in consumption, recycling and substitution ${ }^{2}$, it is inevitable that demand for most mineral commodities will continue to rise. In this article the term "minerals" is used to include naturally occurring construction and industrial materials which will be required for growth and renewal of cities.

- Strategies to decrease carbon intensity involving progressive increases in energy production from renewables, unconventional hydrocarbons (including coal seam and shale gas) and nuclear sources present a range of geoscientific issues.

- Water is essential for the sustenance of all life, agriculture, leisure activities, manufacturing industry and (a small proportion) for mineral and energy production. Greater efficiencies of use cannot avoid increasing demand for this precious resource. Geoscience studies are vital in understanding, husbanding and managing water resources, especially groundwater.

Given ongoing rapid development of the BRIC economies and the inevitable future development of populous African and other countries, new sources of good quality minerals, energy and groundwater will need to be discovered to satisfy demand in the long term.

Finding the massive amounts of natural resources to satisfy the needs of society in the long-term will be challenging and it is important to establish what should be done in the next 10 to 20 years to help. That is the objective of the proposed international collaborative program which IUGS is referring to as Resourcing Future Generations (RFG).

The broad concept is that RFG will last about a decade and be an umbrella activity under which a range of new activities related to securing the mineral, energy and water resources required by future generations can be developed, coordinated and funded. It will provide a bridge between industry, academia and geosurveys, and other Unions under ICSU will be invited to participate.

The purpose of this article is to outline the rationale for RFG, how it will be developed, contextual issues which need to be considered, indicative scientific questions to be considered and the capacity building and training needs.

\section{Rationale}

Our aspiration for the Resourcing Future Generations initiative is relevant groups from governments, universities, and companies around the world working together to improve resource discovery and development. It is proposed that Earth science research driven by the RFG initiative be fully incorporated into Earth System Science programs. In that regard it is hoped that RFG work will be integrated into the major new global initiative "Future Earth", being implemented by a global consortium led by the International Council for Science (ICSU) http://www.icsu.org/future-earth. It is proposed

${ }^{1}$ The term "resources" is used for materials that are potentially available for future use.

${ }^{2}$ Material scientists will continue researching viable substitutes for mineral commodities that are perceived to be in short supply, expensive and/ or environmentally damaging to produce. While this will be significant, it will not preclude the need for new discoveries of currently used commodities. 
that the initial emphasis of RFG will be on mineral resources, with energy and groundwater activities being phased in progressively.

Discovery and production of new mineral resources to satisfy the needs of future generations is a challenging priority. As more land is committed for housing, feeding and servicing people and sustaining natural systems, there are growing restrictions on where mineral explorers can seek new mineral deposits. Furthermore, in wellexplored countries with known high mineral resource potential like Australia, Canada and South Africa, the discovery rates of good quality new mineral deposits is decreasing as the number of easy-to-find near surface deposits remaining to be found diminishes.

In these contexts it will be important that more attention is paid to land use decisions in areas with mineral potential, where conflicting developments are likely. Even with major technological advances, resource extraction activities can be expected to be limited or precluded where the risks of long-term impacts are assessed as unacceptably high, such as in areas of extreme climate and/or topography, or high environmental and/or social values.

New production regions will be needed to secure adequate and reliable supplies of key commodities. Exploration will focus increasingly on deeply buried regions in current mining districts and in regions where a relative paucity of detailed geological knowledge has limited modern exploration, including many poorer countries and remote regions which have considerable, albeit poorly defined, mineral and energy potential.

Responsible mining offers real opportunities for development, but this requires adequate geoscience capacity, legislative frameworks and regulatory regimes. It also requires changing negative perceptions of mining held in some quarters and redesigning the cycle from exploration through production to be more cost effective, less energy and water intensive and environmentally sustainable. These requirements will be addressed in RFG.

For some commodities, it appears that there is unlikely to be shortfalls in supply over the next half century, at least, because of the substantial identified resource base and projected modest growth in demand. An example is uranium (OECD/NEA-IAEA 2011; http:// www.iaea.org/OurWork/ST/NE/NEFW/Technical_Areas/NFC/ uranium-production-cycle-redbook.html) resources of which will be increased further if uranium is extracted from unconventional sources such as rock phosphate. For commodities with rapidly growing demand, there are likely to increasing pressures on the resource base and production capacity by the middle of this century. Bulk commodities such as iron ore and bauxite are notable examples, but also copper and other base metals, fertilizers such as potash and phosphate, and metals with high-technology applications such as platinum group elements and the rare earths.

Geoscientific studies are essential for understanding and managing groundwater systems, including through constraining and groundtruthing computer modelling. In Africa, the major source of drinking water is groundwater and its use for irrigation is forecast to increase substantially to combat growing food insecurity. But groundwater resources are undervalued across the continent and must be revalued there, and in other continents where the resource is threatened.

The search for new energy sources should be driven by industry, and governments must set limits to the use of fossil fuels. Nonetheless, behind the exploration for hydrocarbon sources, there is scope to apply new understanding of fundamental geoscientific concepts in the search for unconventional gas (shale and coal) and oil.

There is a need for a step change in the way we monitor and study the terrestrial subsurface. Society is increasingly using engineered solutions that require a thorough understanding of the subsurface. New resources await discovery along with the development of resilient technologies to extract them. RFG has a critical role to play in improving public understanding of the subsurface and its resources in seeking solutions for energy security and resource management. Its role in inspiring the next generation of geoscientists' is crucial, as is its role in identifying important capacity building and training needs.

Extensive coverage of IUGS member countries and affiliate members will be essential to achieve the RFG programme.

\section{Scoping the new initiative}

IUGS sees its role as catalysing the development and implementation of RFG, in which it would be joined by other interested groups and individuals specialising in a number of relevant disciplines. The Union has established a New Activities Strategic Implementation Committee (NASIC) to scope RFG and the roles of interested parties in more detail. NASIC comprises the authors of this article, who bring broad knowledge and strategic vision:

- Edmund Nickless (Executive Secretary, Geological Society of London) will be the Chair;

- Ian Lambert, Secretary General of the IUGS, will present views from Australasia and be the principal IUGS contact for NASIC;

- John Ludden, Executive Director of the British Geological Survey, will represent the views of geosurveys and related bodies;

- Neil Williams (former CEO of Geoscience Australia and Honorary Professorial Fellow, University of Wollongong) will provide an economic geology, and small to medium sized company perspective;

- Roland Oberhaensli (Professor, Department of Earth and Environmental Science, University of Potsdam and President of IUGS) will provide an academic perspective and link with the International Council for Science (ICSU);

- Marcio Godoy, Global Director Exploration and Project Development, Vale, will represent large industry and South America;

- Pat Leahy (Executive Director, American Geosciences Institute) will bring perspectives from the US, Canada and Mexico;

- Wang AnJian from Chinese Academy of Geological Sciences, will bring a perspective from China, which is a major driver of the rapidly increasing demand for mineral and energy resources, and central and Eastern Asia more broadly;

- Mxolisi Kota (CEO Council for Geosciences, South Africa) will provide an African perspective;

- Ray Durrheim (University of Witwatersrand and AfricaArray) will provide geophysical, capacity building and training inputs.

NASIC will approach its brief by addressing:

1. A series of important inter-related threshold questions on the importance of RFG and how to get interested parties involved, and

2. The potential coverage of RFG.

Each member of NASIC will engage a small consultative group of their choosing to maximise the information and perspectives available to the committee. 
IUGS has charged NASIC to develop a visionary document by mid-October 2013, to set out a roadmap of opportunities in technology, geologic understanding and research and training needs. The key points arising will be incorporated into presentations within a Pardee Keynote Symposium, at the Geological Society of America's Annual meeting in Denver at the end of October, which will introduce RFG to the wider geoscience community.

The developed proposal will be presented to an ICSU GeoUnions meeting to be held in mid-November 2013 in Turkey, which will consider proposals for integration into Future Earth initiative and potential collaboration between disciplines.

It is planned that RFG will be launched at an international meeting on future mineral resources to be held in China in mid-2014.

\section{Threshold questions}

As a starting point, IUGS has posed a number of questions for NASIC, the answer to any of which could give cause to pause and revisit the concept

1. Is RFG a concept worthy of developing?

2. Is IUGS a good organization to develop/coordinate/catalyse RFG as a substantial international program?

3. What other groups should be involved, including details of potential contacts?

4. Who could be leaders/champions of RFG, including details of potential contacts?

5. What would be needed to garner geosurvey interest/support?

6. What would be needed to attract industry interest/support?

7. What is the general approach and indicative timeline recommended to develop and implement RFG?

8. Are there opportunities for developing RFG under a broader global initiative, such as Future Earth, and would this bring benefits?

9. What are potential sources of funding to get the initiative up and running?

\section{Consideration of RFG coverage}

RFG has to be designed to encourage a wide range of parties to be involved. It needs to be broad in scope, with the diverse elements being the responsibility of different groups, and high-level oversight of collaboration and integration.

RFG will have a significant focus on Africa and will exploit indigenous research programs of the nations and initiatives such as the Africa Alive Corridors http://www.sciencedirect.com/science/ article/pii/S1464343X10001792. It will also encompass work on the large datasets from a decade of collaborative geological mapping and geophysical surveys in central and eastern Asia. Further, it is expected to galvanize efforts in other geographic regions one being the remnants of the Tethys belt "Road for geology and Life" where resources of all kinds remain untapped and underexplored and the continental margin magmatic systems are comparable to the Andes. The Tethys domains contain $\sim 70 \%$ of the oil and gas proven reserves on Earth and surely have a lot to deliver, including unconventional hydrocarbon reserves.

A significant outcome will be in capacity building in terms of geological maps/mapping, data management, mineral systems understanding, exploration models, geophysical acquisition programs and integration of geophysical and geological data, etc. RFG will go beyond what exploration companies and national agencies can achieve.

\section{Minerals}

Indicative research and issues under consideration include:

- More detailed evaluations of resource potential in underexplored regions and revisiting of historic mining regions with new technology and concepts. A significant percentage of this activity will be in less developed countries/regions and, amongst other factors, IUGS can bring influence to facilitate work in these areas.

- Evaluation of future global minerals demand and supply.

- The access to new 'big' data systems and breakthroughs in data management and modelling capabilities, including systems for integration of large geophysical and geological data will result in step changes in the understanding and management of resources. RFG must have links to international data initiatives, such as the NSF Earth Cube, http://earthcube.ning.com/, European (http://www.epos-eu.org/, http://geoportal.onegeo logy-europe.org/), Australian (UNCOVER: http://science.org. au/policy/documents/uncover-report.pdf) and other international initiatives.

- Development of novel sensor systems for (geophysical, geochemical) geological assessment, environmental monitoring and possibly underpinning the discovery of big deposits;

- A focus on stress and strain, fluid circulation and chemical and mineralogical changes in the subsurface is needed to understand resources and produce energy from the geosphere and including the protecting of groundwater.

- Satellite and airborne technology with a focus on new systems such as hyperspectral and thermal imaging and use of better digital terrain models to all to allow a 2D mineral maps into a 3D understanding.

- Over a decade we can expect improvement in sensitivity and resolution of radar and satellite systems generally, which will help with more detailed applications, including underground mapping with new gravity systems;

- New sensor systems for the surface and subsurface will be key to provide subsurface measurements and validation of satellite observations. RFG should therefore link to global observation programmes such as the Group on Earth Observations (GEO) and international programmes such as the International Ocean Drilling Program (IODP) and the International Continental Drilling Program (ICDP) and put the case for improvements in sensor technologies which will facilitate discovery and responsible extraction of resources and monitoring and trends in environmental conditions.

- New mineral exploration frontiers for key minerals, most notably the sea-floor.

- Options for sourcing construction materials and industrial minerals.

- Building on Australia's International Mining for Development initiative (http://im4dc.org/) which provides a good example of facilitating establishment of world class mining industries to boost overall economic development. Considerations include:

- Studies of geo-governance and education in relation to conflicts between resources (minerals $v s$ water $v s$ energy), 
and between production of resources and other land uses (agriculture, urbanization, conservation);

- Better analysis of the life cycles of minerals and development of a recycling based economy for key metals and geological commodities;

- Education of the public in acceptance of the need to use the subsurface for mineral extraction and waste management.

- Addressing negative perceptions of mining (http://www.icmm. com/our-work/sustainable-development-framework/10principles).

- Importance of international guidelines and case studies of good practices.

- Engagement with material scientists in considering future materials which could substitute for currently used materials in some applications.

\section{Energy}

The search for new energy sources should be driven by industry, and governments must set limits to the use of fossil fuels. Nonetheless, behind the exploration for hydrocarbon sources, there are fundamental scientific concepts that remain to be proven.

- The origins of carbon, in particular deep carbon in older rocks are enigmatic, as outlined in the Deep Carbon Observatory project https://dco.gl.ciw.edu/. Deep organic synthesis may contribute to the understanding of hydrocarbon energy resources and how they are concentrated in rocks and sediments. This will help the development of the unconventional gas industry (shale and coal gas) and also help in the understanding of how hydrocarbons are preserved. Drilling key transects under different pressure, temperature and fluid flow regimes will be essential to provide underpinning science for this burgeoning global industry.

- Coal, oil and gas extraction should be coupled with carbon capture and storage (CCS) and the scale, cost and capacity of CCS in different regions remain fundamental problems along with understanding water rock interactions, cap-rock integrity, capillary trapping and $\mathrm{CO}_{2}$ solubility and solid state alternatives to underground storage.

- Nuclear energy production brings the geological challenges of siting of reactors and dealing with their waste products. It is an appealing low $\mathrm{C}$ solution for many nations, as exemplified by France which is now $>75 \%$ powered by nuclear energy. Nuclear will be retained as an option and will increase in the energy mix in many countries (e.g. China, Korea, Russia, the UK and the USA) geological solutions are accepted as preferred option for waste containment and storage and will require continued research in underground space of the sort that has been exemplified in the French underground laboratory, by ANDRA http://www.andra.fr/
- As for minerals and generally, a more difficult problem is that of public acceptance of nuclear energy as an environmentally acceptable solution and dealing with the waste issue in a geological context. RFG can play a significant role in educating the public, NGOs and policy makers.

- Scope additional geoscientific issues in relation to future energy resources in consultation with the energy sector and other interested parties.

\section{Groundwater}

In common with the other themes a long-term approach to groundwater will be phased in, developing novel approaches for evaluating groundwater quantities and qualities, recharge rates, linkages between surface and groundwaters and development of new subsurface water storages.

The International Union of Geodesy and Geophysics (IUGG) has been approached about playing a leadership role in identifying the long-term needs for capacity building and research aimed at achieving better understanding and management of water resources.

Although groundwater studies will not be restricted geographically, a focus in RFG is proposed on Africa - to accelerate development and generally improve the quality to life. Groundwater in Africa: Harnessing the hidden sea for climate adaptation, https:// www.gov.uk/government/news/dfid-research-groundwater-inafrica-harnessing-the-hidden-sea-for-climate-adaptation has produced the first set of quantitative continent wide maps of groundwater availability for Africa by utilising existing maps and studies, and undertaking targeted field studies in Nigeria, Tanzania, Uganda and Ethiopia. Defining the resource, its resilience to climate change, over exploitation and contaminations could be on the RFG agenda.

\section{Concluding remarks}

Securing the natural resources needed by future generations will not be easy. It is timely to consider what needs to be done towards that end and the constraints to be faced. The ideas outlined in this paper will be discussed over coming months and it is hoped the RFG would begin in earnest by the third quarter of 2014 .

It is envisaged that the IUGS would play a catalytic and coordinating role in RFG, and that appropriate groups amongst its many member countries, interested affiliate members, research and training groups and resource companies, would participate and contribute relevant experience and expertise.

Finally, the young geoscientists of today and tomorrow have major responsibilities - they need to embrace the vital and proactive roles they will have to play, in collaboration with others, in addressing major challenges in helping secure the natural resources that will be needed by future generations while sustaining the vital Earth systems. 


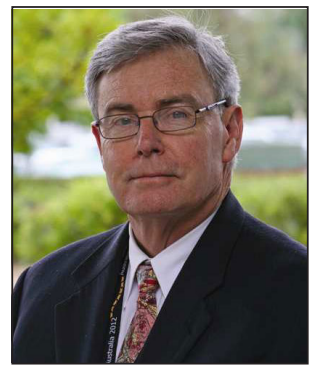

Ian Lambert spent 18 years with CSIRO, conducting research on mineral deposits and stable isotopes. After joining the Australian Government in 1990, he held a number of senior advisory roles in environmental and resource agencies, most recently with Geoscience Australia. He was Secretary General of the $34^{\text {th }}$ International Geological Congress, held in Brisbane in August 2012, where he was elected Secretary General of the IUGS.

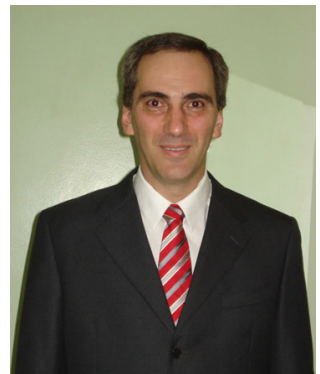

Marcio Godoy is presently the head for Mineral Exploration and Project Development at Vale and serves as President of the Brazilian Mining Industry Development Agency - ADIMB. He is also a member of the board of Vale Foundation, Vale's arm responsible for the sustainable development initiatives in areas in which Vale is active in Brazil and overseas.

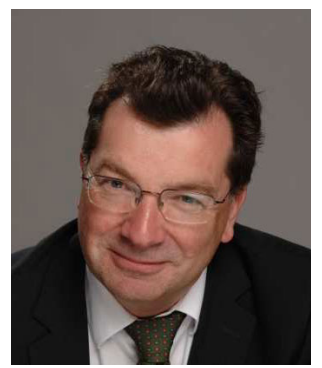

John Ludden is currently the Executive Director of the British Geological Survey and serves on the Executive Committee of the Natural Environment Research Council, UK. He is also a Research Director (Classe exceptionnelle) of the Centre National de Recherche Scientifique (CNRS) where he was Associate Director for Earth Sciences and also at the Institut de Physique du Globe, Paris.

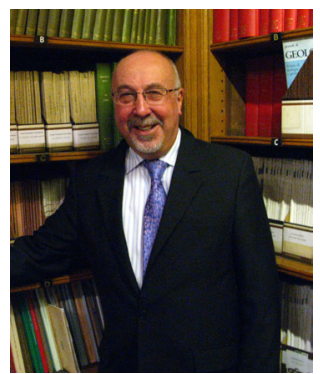

Edmund Nickless has been Executive Secretary of the Geological Society of London since 1997. Previously he held senior posts within the British Geological Survey, the then Science and Technology Secretariat of the Cabinet Office and the Natural Environment Research Council. $\mathrm{He}$ is a European Geologist and Chartered Geologist.

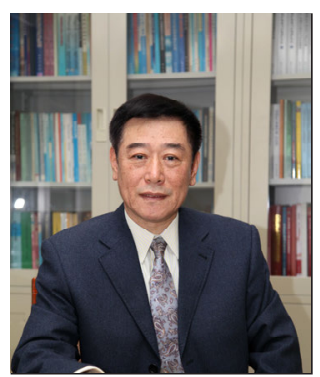

Wang Anjian is currently a professor with Chinese Academy of Geological Sciences, and serves as the director of Research Center for Strategy of Global Mineral Resources, CAGS and director of World Data Center for Geology, China. He has long been engaged in research and education in economic geology, metallogeny and strategy of mineral resources.

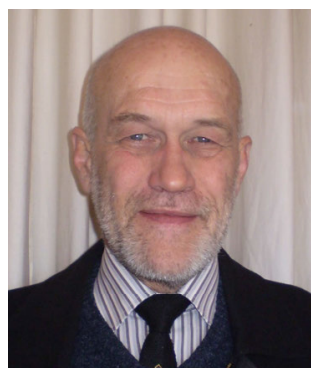

Ray Durrheim holds the South African Research Chair in Exploration, Earthquake \& Mining Seismology and a joint appointment at the CSIR Centre for Mining Innovation and the University of the Witwatersrand. He is co-director of the AfricaArray capacity-building and research programme. His research interests include seismic investigations of the African lithosphere, and rockburst damage mechanisms.

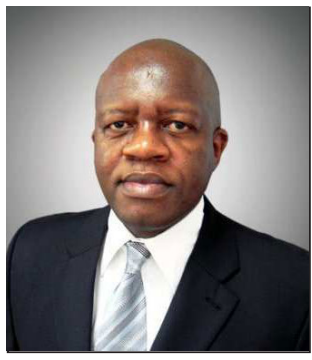

Mxolisi Kota is the CEO of Council for Geoscience, South Africa. He is a registered Professional Natural Scientist (Pr.Sci.Nat.), a Fellow of the Society of Economic Geologists (SEG) and a Member of both the Geological Society of South Africa (GSSA) and Southern African Institute of Mining and Metallurgy (SAIMM). Mxolisi also serves on the governing council of the GSSA.

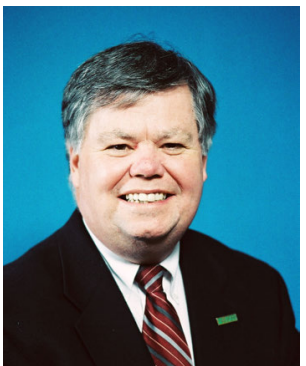

P. Patrick Leahy is Executive Director of the American Geosciences Institute of Alexandria, Virginia. Leahy served as US GS's Associate Director for Geology, responsible for Federal basic earth science programs, including earthquake hazards monitoring and research, and geologic mapping of land and seafloor resources. $\mathrm{He}$ has specialized in regional groundwater studies.

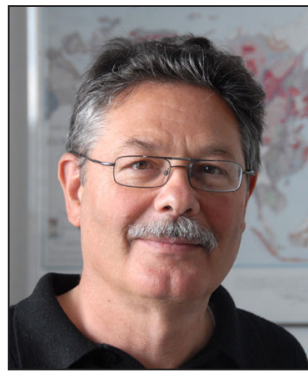

Roland Oberhänsli is Professor of Mineralogy at the Institute of Earth \& Environmental Sciences of Potsdam University in Germany. He is a metamorphic petrologist working on Tethyan HP rocks from the Alps to the Himalaya. He serves as co-ordinator of the German National ICDP program. Currently he is the President of the IUGS.

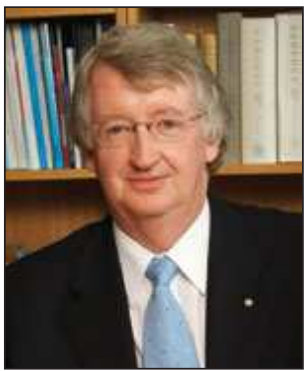

Neil Williams has worked in a diverse range of positions relevant to mineral exploration in academia, industry, and government. In 1991 he joined the Australian Public Service (APS) and was CEO of Geoscience Australia. He was President of the $34^{\text {th }}$ International Geological Congress held in Brisbane in August 2012. 